\title{
Metabolic syndrome in a sample of the 6- to 16-year-old overweight or obese pediatric population: a comparison of two definitions
}

This article was published in the following Dove Press journal:

Therapeutics and Clinical Risk Management

I February 2012

Number of times this article has been viewed

\section{Fatemeh Saffari \\ Shabnam Jalilolghadr \\ Neda Esmailzadehha \\ Peyman Azinfar}

Qazvin Children Hospital, Qazvin University of Medical Sciences, Qazvin, Iran
Correspondence: Shabnam Jalilolghadr Clinical Research Center, Qazvin Children's Hospital, Qazvin University of Medical Sciences, Qazvin, Iran

Tel +989122814230

Fax +98 28I 3344088

Emailshabnam_jalilolgadr@yahoo.com
Purpose: The purpose of this study was to estimate the presence of metabolic syndrome (MS) in a group of children and adolescents with a body mass index (BMI) above the 85th percentile for their age and sex in Qazvin Province, Iran; to evaluate the relationship between obesity and metabolic abnormalities; and to compare two proposed definitions of MS.

Patients and methods: The study was conducted on 100 healthy subjects aged between 6 and 16 years (average age, $10.52 \pm 2.51$ years) with a high BMI for their age and sex. Fifty-eight percent of subjects were female. Physical examination including evaluation of weight, height, BMI, and blood pressure measurement was performed ("overweight" was defined as a BMI between the 85 th and 95 th percentiles for children of the same age and sex; "obese" was defined as a BMI over the 95th percentile for children of the same age and sex). Blood levels of glucose, insulin, total cholesterol, high-density lipoprotein cholesterol, low-density lipoprotein cholesterol, triglycerides, and uric acid were measured after a 12-hour overnight fast. The authors used and compared two definitions of MS: the National Cholesterol Education Program's Adult Treatment Panel III (NCEP ATP III) criteria and a modified definition by Weiss et al. Variables were compared using the Student's $t$-test and chi-square and Mann-Whitney $U$ tests, and agreement between the two definitions was analyzed using kappa values.

Results: The subjects had a mean BMI of $26.02 \pm 4.38$ and $80 \%$ had obesity. Insulin resistance was found in $81 \%$ of the study population. MS was present in ten $(50 \%)$ of the overweight and $53(66.2 \%)$ of the obese subjects using the NCEP ATP III criteria. MS was present in five $(25 \%)$ of the overweight and $34(42.5 \%)$ of the obese subjects using the definition by Weiss et al. The overall kappa value for the two definitions of MS was 0.533 . There were no statistically significant differences between the two definitions of MS in participants.

Conclusion: The prevalence of MS in children and adolescents depends on the criteria chosen and their respective cutoff points. The NCEP ATP III criteria, the parameters of which include higher cutoff values for high-density lipoprotein cholesterol and triglycerides, detected the higher prevalence and therefore the NCEP ATP III criteria are able to diagnose a larger number of children and adolescents at metabolic risk.

Keywords: children, adolescents, obesity, body mass index, metabolic syndrome

\section{Introduction}

The prevalence of childhood obesity has more than doubled in the last 2 decades in many countries and it is now considered a serious medical and public health problem globally. ${ }^{1-3}$ Obesity causes sleep apnea and psychological problems in childhood and it increases the risk of cardiovascular disease, diabetes, hypertension, dyslipidemia, osteoarthritis, and cancer in future life..$^{1,4,5}$ 
Hanefeld and Leonhard ${ }^{6}$ first discussed metabolic syndrome (MS) in 1981. In 1988, Reaven ${ }^{7}$ described it as a link between insulin resistance (IR) and hypertension, dyslipidemia, type 2 diabetes, and other metabolic abnormalities that are associated with an increased risk of atherosclerotic cardiovascular disease in adulthood.?

It has been suggested that MS may originate in the uterus. ${ }^{8,9}$ Genetic factors or adverse events in early life or a sedentary lifestyle may cause MS and its complications, especially in non- European populations. ${ }^{10-12}$ IR has been recognized in the pathogenesis of the syndrome, and childhood obesity is the most common feature associated with IR., ${ }^{73}$

Few studies have estimated the prevalence of MS in children and adolescents, ${ }^{14}$ and diagnostic criteria have not been standardized. ${ }^{15-17}$ Definitions agree on the essential components of the syndrome but there are differences in some diagnostic criteria. ${ }^{13,18}$ Although, the accuracy of present MS definitions is under debate, it seems that MS screening in the overweight and obese pediatric population and comparison of different suggested criteria is essential.

The aim of this study was to estimate the presence of MS in a group of children and adolescents with a BMI above the 85th percentile for their age and sex in Qazvin Province, Iran, to evaluate the relationship between obesity and metabolic abnormalities, and to compare two proposed definitions of MS.

\section{Material and methods}

This study was conducted with 100 children and adolescents (calculated sample size was 83 persons, considering $Z=1.96$, expected prevalence or proportion was $31.9 \%$, and precision was 0.07 ) living in Qazvin Province. Qazvin is a city located about $150 \mathrm{~km}$ west of Tehran, the capital of Iran. Overweight and obese subjects were referred to the authors' pediatric endocrine clinic by their general practitioner or primary care pediatric consultant between 2009 and 2010 .

The subjects were healthy, aged between 6 and 16 years old (average age, $10.52 \pm 2.51$ years), and had a body mass index (BMI) above the 85th percentile for their age and sex. Fifty-eight percent of the subjects were female. "Overweight" was defined as a BMI between the 85th and 95th percentiles for children of the same age and sex; "obese" was defined as a BMI over the 95th percentile for children of the same age and sex. ${ }^{19}$ Subjects with diabetes and who were under treatment with medication that influences blood pressure (BP), blood glucose, or lipid metabolism were excluded from the study. Children with secondary obesity due to drugs or endocrine or genetic disorders were also excluded from the study.
The ethics committee of Qazvin University of Medical Sciences approved the study. Written informed consent from both the participants and their parents was obtained.

Demographic characteristics were noted in a questionnaire given to participants. A pediatric endocrinologist performed the physical examination of the subjects, which included an evaluation of weight, height, BMI, and BP measurement, with special attention given to the existence of acanthosis nigricans, defined as the thickening and darkening of the upper layers of the skin of the posterior neck, axilla, elbows, or knees. ${ }^{20}$

Height was measured twice, while subjects were barefoot, to an accuracy of $\pm 0.1 \mathrm{~cm}$. Weight was measured twice, while subjects were lightly dressed, to an accuracy of $\pm 0.1 \mathrm{~kg}$. BMI was calculated by dividing the weight $(\mathrm{kg})$ by the square of the height (m). Waist circumference (WC) was measured to an accuracy of $\pm 0.2 \mathrm{~cm}$ with a nonelastic measuring tape. WC was measured at a point halfway between the lower border of the thorax and the iliac crest at the end of expiration. ${ }^{21}$

BP was measured with a mercury sphygmomanometer after a 5-minute rest. Systolic and diastolic BPs were taken twice, with the patient sitting down. Appropriately sized BP cuffs were used, with the width of the cuff being $40 \%$ of the mid-arm circumference, and with cuff bladders covering $80 \%-100 \%$ of the arm circumference and approximately twothirds of the length of the upper arm, without overlapping. The readings at the first and fifth phases of Korotkoff sounds were considered as the systolic BP and the diastolic BP, respectively. ${ }^{22}$ Elevated systolic or diastolic BP was defined in two ways, on the basis of the definitions of MS, as a value exceeding the 90th percentile in NCEP ATP III definition or the 95th percentile in Weiss et al's definition ${ }^{12}$ for age, sex and height.

Venous blood samples were obtained from subjects after a 12-hour overnight fast. Blood levels of glucose, insulin, total cholesterol, high-density lipoprotein cholesterol (HDL-C), low-density lipoprotein cholesterol (LDL-C), triglycerides (TGs), and uric acid were measured in all patients. All biochemical measurements were performed in one laboratory.

A Selectra E analyzer with photometric assay and reagent (Parsazmun Company, Tehran, Iran) was used to measure fasting blood sugar (FBS); mean intra- and interassay coefficients of variation (CVs) were $1.28 \%$ and $0.84 \%$, respectively. Impaired glucose tolerance was defined as a glucose level greater than $140 \mathrm{mg} / \mathrm{dL}$ but then less than $200 \mathrm{mg} / \mathrm{dL}$ at 2 hours. Insulin levels were measured by electrochemiluminescence immunoassay using reagent (Roche Diagnostics GmbH, Germany). A within-run precision CV was $1.9 \%$ and total precision $\mathrm{CV}$ was $1.45 \%$. The degree of 
IR was determined with the use of a homeostatic model, and calculated as the product of the fasting plasma insulin level $(\mu \mathrm{lU} / \mathrm{mL})$ and the fasting plasma glucose level (mmol/L), divided by $22.5 .{ }^{23}$ IR was defined as a homeostasis model of insulin resistance (HOMA-IR) value of more than 1.775. ${ }^{24}$

A Selectra E analyzer with photometric assay and reagent (Parsazmun Company) was also used to measure cholesterol, HDL-C, LDL-C, TGs, and serum uric acid; mean intra- and interassay CVs for cholesterol were $1.82 \%$ and $1.04 \%$, respectively; for HDL-C, they were $0.73 \%$ and $1.8 \%$, respectively; for LDL-C, $0.66 \%$ and $1.45 \%$, respectively; for TGs, $1.82 \%$ and $1.04 \%$, respectively; and for serum uric acid, $1.18 \%$ and $1.13 \%$, respectively.

Since there is no single internationally accepted definition of MS for children and adolescents, the authors used and compared two definitions. The diagnostic criteria of these definitions are shown in Table 1. The first definition used was similar to de Ferranti et al's ${ }^{16}$ definition of MS, which is based on criteria analogous to the National Cholesterol Education Program's Adult Treatment Panel III (NCEP ATP III) criteria. ${ }^{25}$ It should be added that de Ferranti et al ${ }^{16}$ used the cutoff of FBS $\geq 110 \mathrm{mg} / \mathrm{dL}$, but the present authors decided to, like recent studies, follow the latest recommendation of the American Diabetes Association. ${ }^{11}$ The National Heart, Lung, and Blood Institute's recommended cutoff point for BP was used also. The second definition was a modified definition by Weiss et al, ${ }^{12}$ in which WC and FBS criteria were similar to the first definition.

Kolmogorov-Smirnov test was used to examine the normality of variables. Data were reported as mean plus or minus standard deviation for normally distributed variables or as median (minimum to maximum) for non-normally distributed variables. Categorical variables were analyzed by chi-square test, continuous variables were compared using Student's $t$-test, and non-normally distributed variables were analyzed by Mann-Whitney $U$ test. Agreement between the two MS definitions was analyzed using the kappa value, which was considered excellent for values greater than 0.81 , good for values $0.61-0.80$, moderate for $0.41-0.60$, and weak for values less than $0.4 .{ }^{26} \mathrm{~A} P$-value less than 0.05 was considered statistically significant.

\section{Results}

The 100 participants had a mean BMI of $26.02 \pm 4.38$. Of the 100 participants, 20 subjects were overweight and 80 were obese. WC in 81 subjects was more than the upper limit of normal, and it ranged from 68 to $118 \mathrm{~cm}$. Waist-tohip ratio (WHR) was more than the upper limit of normal in all of the females in the study (WHR more than 0.7 ) and in 40 of the males (WHR more than 0.8). WC and WHR were significantly different between overweight and obese subjects. Eleven overweight subjects and 70 obese subjects had a high WC, and 98 subjects had a high WHR. Forty-eight subjects had acanthosis nigricans. The ratio of LDL-C to HDL-C varied from 1.0 to 10.6 (by a mean value of $2.48 \pm 1.30$ ). HOMA-IR values ranged from 1.0 to 20.48. IR was found in 81 subjects. The clinical and biochemical characteristics of the population are shown in Tables 2 and 3. With respect to all biochemical characteristics, the difference between overweight and obese subjects was not significant.

\section{Results by NCEP ATP III criteria}

Sixty-three patients met the criteria for MS as defined by the NCEP ATP III. It was present in ten (50\%) of the overweight and $53(66.2 \%)$ of the obese subjects. Hypertension was detected in $36 \%$ of subjects (34\% systolic and $24 \%$ diastolic hypertension). Values of every component of the definition other than WC values were significantly different between subjects with and without MS.

The prevalence of each component of MS in both groups of subjects is reported in Table 4. High serum levels of TGs, cholesterol, LDL-C, uric acid, and FBS were reported in 74, 31, 17, eight, and twelve children, respectively. The low level of HDL-C was 70\%. The most frequent component of MS was high WC followed by high TGs and low HDL-C. MS was not significantly different between males and females $(P=0.402)$.

Table I Diagnostic criteria for two definitions of metabolic syndrome

\begin{tabular}{lll}
\hline Component & Weiss et al ${ }^{12}$ (any three of these criteria) & NCEP ATP III (any three of these criteria) \\
\hline Glucose & FPG $\geq 100 \mathrm{mg} / \mathrm{dL}$ & FPG $\geq 100 \mathrm{mg} / \mathrm{dL}$ \\
WC & WC $\geq 75$ th percentile for age and sex & WC $\geq 75$ th percentile for age and sex \\
TGs & Fasting TGs $\geq$ fifth percentile for age and sex & Fasting TGs $\geq 100 \mathrm{mg} / \mathrm{dL}$ \\
HDL-C & $\mathrm{HDL}<$ fifth percentile for age and sex & $\mathrm{HDL}<50 \mathrm{mg} / \mathrm{dL}(<45 \mathrm{mg} / \mathrm{dL}$ in males over I5 years old) \\
BP & SBP/DBP $>95$ th percentile for age and sex & SBP/DBP $>90$ th percentile for age and sex \\
\hline
\end{tabular}

Abbreviations: BP, blood pressure; DBP, diastolic blood pressure; FPG, fasting plasma glucose; HDL, high-density lipoprotein; HDL-C, high-density lipoprotein cholesterol; NCEP ATP III, National Cholesterol Education Program's Adult Treatment Panel III criteria; SBP, systolic blood pressure; TGs, triglycerides; WC, waist circumference. 
Table 2 Clinical and laboratory characteristics of subjects

\begin{tabular}{|c|c|c|c|c|}
\hline Characteristic & Total & Overweight $(n=20)$ & Obese $(n=80)$ & $P$-value \\
\hline $\operatorname{Sex}(M / F)$ & $42 / 58$ & $4 / 16$ & $38 / 42$ & 0.022 \\
\hline Age (years)* & $10.52 \pm 2.51$ & $11.68 \pm 2.90$ & $10.23 \pm 2.33$ & 0.020 \\
\hline BMI $\left(\mathrm{kg} / \mathrm{m}^{2}\right)^{*}$ & $26.02 \pm 4.38$ & $22.95 \pm 2.56$ & $26.72 \pm 4.4 \mathrm{I}$ & $<0.001$ \\
\hline $\mathrm{WC}(\mathrm{cm})^{*}$ & $85.82 \pm 12.77$ & $79.61 \pm 7.75$ & $87.24 \pm 13.29$ & 0.021 \\
\hline Hip circumference $(\mathrm{cm})^{*}$ & $95.44 \pm 11.54$ & $92.20 \pm 8.23$ & $96.25 \pm 12.13$ & NS \\
\hline WHR* & $0.898 \pm 0.068$ & $0.87 \pm 0.056$ & $0.904 \pm 0.069$ & 0.047 \\
\hline TGs $(\mathrm{mg} / \mathrm{dL})^{* *}$ & $\mid 40(4 \mid-750)$ & $135(9 \mid-750)$ & $\mid 46.5(4 \mid-658)$ & NS \\
\hline Total cholesterol (mg/dL)* & $171.09 \pm 45.14$ & $181.75 \pm 70.4$ & $168.42 \pm 36.4$ & NS \\
\hline $\mathrm{HDL}-\mathrm{C}(\mathrm{mg} / \mathrm{dL})^{*}$ & $43.462 \pm 10.99$ & $43.5 \pm 11.36$ & $43.45 \pm 10.96$ & NS \\
\hline LDL-C (mg/dL)* & $100.84 \pm 34.07$ & $106.75 \pm 51.49$ & $99.36 \pm 28.39$ & NS \\
\hline $\mathrm{SBP}(\mathrm{mmHg})^{*}$ & $111.60 \pm 12.38$ & $109.20 \pm 14.01$ & $112.20 \pm 12.54$ & NS \\
\hline $\mathrm{DBP}(\mathrm{mmHg})^{*}$ & $67.26 \pm 10.28$ & $65.80 \pm 10.98$ & $67.62 \pm 10.13$ & NS \\
\hline Fasting blood glucose $(\mathrm{mg} / \mathrm{dL})^{*}$ & $90.65 \pm 7.91$ & $89 \pm 7.38$ & $91.06 \pm 8.03$ & NS \\
\hline Blood glucose after 2 hours $(\mathrm{mg} / \mathrm{dL}) *$ & $102.02 \pm 22.05$ & $94.5 \pm 27.02$ & $103.9 \pm 20.4$ & NS \\
\hline Fasting insulin $(\mu \mathrm{IU} / \mathrm{mL})^{* *}$ & $16.3(5.7-76.8)$ & $15.2(6.1-48.1)$ & $17.25(5.7-76.8)$ & NS \\
\hline Insulin after 2 hours $(\mu \mathrm{lU} / \mathrm{mL})^{* *}$ & $58.5(6.2-35 \mathrm{I})$ & $55.8(18.2-248.2)$ & $60.7(6.2-35 I)$ & NS \\
\hline HOMA-IR** & $3.57(\mathrm{I}-20.48)$ & $2.96(I-10.22)$ & $3.87(1.05-20.48)$ & NS \\
\hline $\operatorname{IR}(n)$ & 81 & 16 & 65 & NS \\
\hline Uric acid $(\mathrm{mg} / \mathrm{dL})^{*}$ & $5.2 \pm 1.17$ & $5.06 \pm 1.1$ & $5.24 \pm 1.19$ & NS \\
\hline
\end{tabular}

Notes: *Data presented as mean plus or minus standard deviation; **data presented as median (minimum to maximum).

Abbreviations: BMI, body mass index; DBP, diastolic blood pressure; HDL-C, high-density lipoprotein cholesterol; HOMA-IR, homeostasis model of insulin resistance; IR, insulin resistance; LDL-C, low-density lipoprotein cholesterol; NS, not significant; SBP, systolic blood pressure; TGs, triglycerides; WC, waist circumference; WHR, waist-to-hip ratio.

In spite of fasting insulin, HOMA-IR was not statistically different between subjects with and subjects without MS. Overall, MS was observed in $64.2 \%$ of patients with IR, compared with $57.9 \%$ for those without, but the difference was not significant.

\section{Results by Weiss et al's ${ }^{12}$ definition}

Thirty-nine patients met the criteria for MS as defined by Weiss et al. ${ }^{12}$ It was present in five $(25 \%)$ of the overweight and $34(42.5 \%)$ of the obese subjects. Hypertension was detected in $34 \%$ of subjects (33\% systolic and $23 \%$ diastolic hypertension). Values of every component of the definition between subjects with and without MS were significantly different. In addition, BMI and hip circumference values were statistically different between these two groups.

The most frequent component of MS was high WC, followed by high TGs and then hypertension (see Table 4). MS was not significantly different between males and females $(P=0.304)$. Fasting insulin and HOMA-IR values were statistically different between subjects with and subjects without MS. Overall, MS was observed in $43.6 \%$ of patients with IR, as compared with $26.3 \%$ for those without, but the difference was not significant.

In both definitions, subjects with MS had lower insulin sensitivity parameters and higher oral glucose tolerance test and uric acid levels than those subjects without MS, but the difference was not significant. The values of every component of the two MS definitions were compared among subjects diagnosed with MS but no significant differences were found (FBS, 0.22; WC, 0.86; HDL-C, 0.59; TGs, 0.628; BP, 0.103). When the frequency of the different components of MS in overweight and obese patients was compared, there were no significant differences found with respect to hypertension, low HDL-C, high TGs, and FBS.

As expected, abdominal obesity was the most frequent criterion (81\%) in overweight and obese children and adolescents, followed by a high TG level.

The overall kappa value for the two definitions of MS was 0.533. To examine possible causes of moderate agreement between the definitions, the authors compared agreement between the criteria of the two MS definitions in the study population. The kappa values were 0.308 and 0.728 for HDL-C and TGs, respectively.

\section{Discussion}

MS is one of the most important and serious challenges in global health in the modern world. The authors found a high prevalence of MS (42.5\%) in the obese children, while prevalence was $25 \%$ in the overweight children. Abdominal obesity, a criterion of MS, also presented in a significant portion of the obese and overweight children. Among children and adolescents of Caucasian origin in Italy, the prevalence 
Table 3 Clinical and laboratory characteristics of subjects for each group of criteria

\begin{tabular}{|c|c|c|c|c|c|c|}
\hline \multirow[t]{2}{*}{ Characteristic } & \multicolumn{3}{|l|}{ NCEP ATP III } & \multicolumn{3}{|l|}{ Weiss et $\mathrm{al}^{12}$} \\
\hline & MS $(n=63)$ & No MS $(n=37)$ & $P$-value & MS $(n=39)$ & No MS $(n=61)$ & $P$-value \\
\hline $\operatorname{Sex}(M / F)$ & $24 / 39$ & $18 / 19$ & NS & $19 / 20$ & $24 / 37$ & NS \\
\hline Age (year)* & $10.72 \pm 2.49$ & $10.19 \pm 2.50$ & NS & $11.06 \pm 2.19$ & $10.07 \pm 2.58$ & NS \\
\hline BMI $\left(\mathrm{kg} / \mathrm{m}^{2}\right)^{*}$ & $26.43 \pm 3.81$ & $25.27 \pm 5.24$ & NS & $27.45 \pm 3.77$ & $25.06 \pm 4.5 \mathrm{I}$ & 0.008 \\
\hline $\mathrm{WC}(\mathrm{cm})^{*}$ & $87.31 \pm 10.17$ & $83.07 \pm 16.37$ & NS & $89.80 \pm 9.92$ & $83.15 \pm 13.82$ & 0.011 \\
\hline Hip circumference $(\mathrm{cm})^{*}$ & $0.90 \pm 0.05$ & $93.42 \pm|3.5|$ & NS & $99.07 \pm 8.96$ & $92.64 \pm 12.59$ & 0.007 \\
\hline WHR* & $0.902 \pm 0.069$ & $0.89 \pm 0.08$ & NS & $0.90 \pm 0.05$ & $0.893 \pm 0.075$ & NS \\
\hline TGs $(\mathrm{mg} / \mathrm{dL})^{* *}$ & $175(9 \mid-750)$ & $92(4 I-177)$ & $<0.001$ & $184(1 \mid 10-750)$ & I I 8.5 (4I-259) & $<0.001$ \\
\hline Total cholesterol $(\mathrm{mg} / \mathrm{dL})^{*}$ & $180.06 \pm 48.47$ & $154.79 \pm 35.22$ & 0.009 & $183.79 \pm 52.92$ & $162.74 \pm 38.38$ & 0.025 \\
\hline HDL-C (mg/dL)* & $40.67 \pm 9.16$ & $48.91 \pm 12.32$ & 0.001 & $39.59 \pm 11.02$ & $46.22 \pm 10.31$ & 0.003 \\
\hline LDL-C (mg/dL)* & $105.77 \pm 37.28$ & $92.22 \pm 27.01$ & NS & $107.82 \pm 40.78$ & $96.45 \pm 29.4$ & NS \\
\hline $\mathrm{SBP}(\mathrm{mmHg})$ & $31(49.2)$ & $3(8.1)$ & 0.000 & $25(64.1)$ & $8(13.8)$ & 0.000 \\
\hline $\mathrm{DBP}(\mathrm{mmHg})$ & $23(36.5)$ & I (2.27) & 0.000 & $19(48.7)$ & $4(6.9)$ & 0.000 \\
\hline Hypertension ( $n$ ) & $33(52.4)$ & $3(8.1)$ & 0.000 & $27(69.2)$ & $8(12)$ & 0.000 \\
\hline Fasting blood glucose (mg/dL)* & $91.98 \pm 7.66$ & $88.35 \pm 8.20$ & 0.032 & $93.89 \pm 7.52$ & $88.56 \pm 7.66$ & 0.001 \\
\hline Blood glucose after 2 hours $(\mathrm{mg} / \mathrm{dL})^{*}$ & $104.65 \pm 17.11$ & $97.54 \pm 28.29$ & NS & $105.38 \pm 18.76$ & $99.68 \pm 24.30$ & NS \\
\hline Fasting insulin $(\mu \mathrm{lU} / \mathrm{mL})^{* *}$ & 19.1 (6.I-76.8) & I I.8 (5.7-60) & 0.048 & $21.5(6.1-76.8)$ & $12.6(5.7-60)$ & 0.001 \\
\hline Insulin after 2 hours $(\mu \mathrm{IU} / \mathrm{mL})^{* *}$ & $67.15(9.2-35 I)$ & $44(6.2-138.7)$ & 0.001 & $62(9.2-35 I)$ & $56.9(6.2-211.3)$ & NS \\
\hline HOMA-IR** & $4.28(I-20.48)$ & $2.96(1.05-19.77)$ & NS & $4.88(1-20.48)$ & $3.11(1.05-19.77)$ & 0.004 \\
\hline $\operatorname{IR}(\mathrm{n})$ & 52 & 29 & NS & 34 & 47 & NS \\
\hline Uric acid $(\mathrm{mg} / \mathrm{dL})^{*}$ & $5.33 \pm 1.18$ & $4.93 \pm 1.12$ & NS & $5.44 \pm 1.10$ & $5.01 \pm 1.19$ & NS \\
\hline
\end{tabular}

Notes: *Data presented as mean plus or minus standard deviation; **data presented as median (minimum to maximum).

Abbreviations: BMI, body mass index; DBP, diastolic blood pressure; HDL-C, high-density lipoprotein cholesterol; HOMA-IR, homeostasis model of insulin resistance; IR, insulin resistance; LDL-C, low-density lipoprotein cholesterol; MS, metabolic syndrome; NCEP ATP III, National Cholesterol Education Program's Adult Treatment Panel III criteria; NS, not significant; SBP, systolic blood pressure; TGs, triglycerides; WC, waist circumference; WHR, waist-to-hip ratio.

of MS has been reported to be higher in severely obese subjects $(31.1 \%)$ than moderately obese subjects $(12.0 \%)$, and none of the overweight or normal-weight children studied had MS. ${ }^{27}$ Weiss et $\mathrm{al}^{12}$ also stated that risk of MS increases with the degree of obesity.

The prevalence of MS in the present study is higher than reported in European countries. ${ }^{18,28-31}$ The overall prevalence of MS in obese children and adolescents has been reported as $18 \%$ in Spain, ${ }^{13} 13.9 \%$ in Italy, ${ }^{27} 33 \%$ in the United Kingdom, ${ }^{30} 30 \%$ in Hispanic children in North America, ${ }^{31}$ $27.2 \%$ in Turkey, ${ }^{32} 17.3 \%$ in Brazil, ${ }^{33} 15.9 \%$ in France,,${ }^{34}$ and $8.9 \%$ in Hungary. ${ }^{35}$

The differences among studies can originate from the different definitions used for childhood MS. In an article on obese French children, the frequency of MS was found to be $15.9 \%$ when using the NCEP ATP III criteria; however, the frequency reached $42.5 \%$ when using the World Health Organization's insulin resistance syndrome definition. ${ }^{36}$ In the present study, the frequency of MS was $63 \%$ when using the NCEP ATP III; however, the frequency changed to $39 \%$ when using Weiss et al's ${ }^{12}$ definition. Agreement between the definitions used was moderate.

Males usually present higher frequencies of $\mathrm{MS} .{ }^{28,37}$ In a large US population study concerning adolescents aged
12-19 years, MS was found to be about three times more prevalent in males. ${ }^{37}$ Other studies have reported a slightly higher prevalence of MS in females than males. ${ }^{38,39}$ However, a significant difference in the prevalence of MS according to sex was not found in the present study.

Childhood obesity is associated with cardiovascular and metabolic disturbances. ${ }^{40}$ In the present study, several parameters failed to present a significant difference between overweight and obese children, except for significantly higher WCs in the obese group.

Elevated BP was detected in about one-third of the sample. The frequency of elevated BP reported in obese children from several European countries (38\% $)^{41}$ and from the United States ${ }^{42}$ is similar to that found in the present study, but a higher frequency has been reported in 7- to 9-year-old Portuguese schoolchildren. ${ }^{28}$ High BP has been reported to be responsible for MS in $44.7 \%$ of Italians and in $66.1 \%$ of Germans. ${ }^{29}$ The differences found may be attributable to different dietary habits, such as sodium intake, in populations.

The present authors observed that children with MS presented a higher BMI and significant differences in clinical and biochemical characteristics than those children without MS. The reason why some obese children develop MS while others do not is still unclear. ${ }^{42}$ 


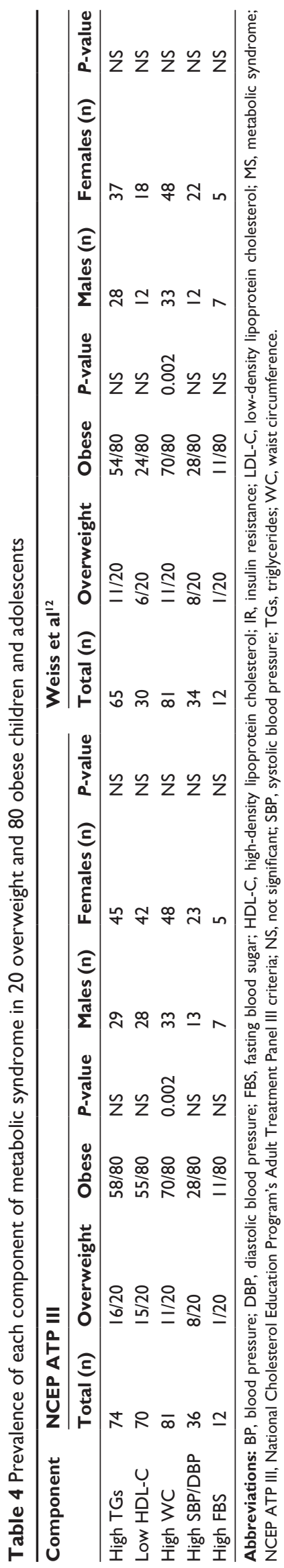

It is well discussed that atherosclerosis begins in childhood and is associated with several MS risk factors. High TG and LDL levels and low HDL levels are the most important atherogenic factors in children with MS. ${ }^{13,28}$ In the present study, the children with MS presented acanthosis, elevated insulin levels, and increased HOMA-IR values. Acanthosis nigricans is associated in some cases with hyperinsulinemia. ${ }^{20}$ Children with this characteristic are 1.6 times $^{43}$ to 4.2 times $^{44}$ more prone to having hyperinsulinemia. Typical areas of involvement include the posterior neck, the axilla, the elbows, and the knees.

In the current study the difference of insulin level when using Weiss et al's ${ }^{12}$ definition was significant. IR was found in $81 \%$ of the study population, while high fasting glycemia was $12 \%$. However, high fasting glycemia was not common in the subjects. This suggests that an impaired glucose level develops later than the other MS components, while IR is the earlier abnormality of glucose metabolism in obesity ${ }^{45}$ Actually, excess weight in children and adolescents may serve as an accelerator for the onset of type 2 diabetes in childhood. ${ }^{28,46}$ IR seems to be an important pathophysiologic factor for MS, becoming more important than overall adiposity in the development of the syndrome. ${ }^{28,47}$ In a recent publication, Voss et $\mathrm{al}^{48}$ showed that discrimination between overweight and obesity using BMI in young children was not a good marker for the prediction of IR or, therefore, for the prediction of metabolic risk.

It is recognized that MS in a person's youth can increase risk of developing type 2 diabetes and cardiovascular disease in adulthood. ${ }^{49}$ It is not clear which set of metabolic abnormalities will evolve toward a more serious sequel of MS or, conversely, which one is potentially more reversible by treatment in the future. ${ }^{29}$ However, it is obvious that treatment and prevention of MS in obese youth is necessary. In spite of the high prevalence of MS observed in obese youth from different studies, there are reports that lifestyle modification for young people has led to changes in single components and reduction of MS prevalence. ${ }^{50,51}$ Early diagnosis and treatment of weight excess in overweight subjects would prevent the health complications of obesity in adulthood.

There is no consensus about the definition of MS in children. ${ }^{52}$ Different MS criteria have been employed for different studies in children and adolescents, and the components and cutoffs used to diagnose the syndrome have varied among the various definitions. ${ }^{12,37,52}$ Because of the age- and sex-dependent changes in several components of MS, adult definitions of MS do not apply to children. ${ }^{53}$ Growth and developmental effects during childhood and adolescence 
make it difficult to choose a distinct cutoff for risk factors. ${ }^{54}$ As a result, the prevalence varies according to the definition used. ${ }^{52}$ This point is corroborated by the present study, as the authors found a wide range of prevalence between the two definitions used.

The major criteria of MS came from the NCEP ATP III in 2001. Weiss et al's ${ }^{12}$ definition is a slightly modified version of the NCEP ATP III criteria. The cutoff values for TGs and HDL-C are the main difference between the NCEP ATP III and Weiss et al's ${ }^{12}$ definition. Results of this study demonstrated that the prevalence of MS found when using the NCEP ATP III definition was higher than when using the definition by Weiss et al. ${ }^{12}$ One of the reasons for these differences could be that lipid profile and BP criteria are higher in the NCEP ATP III definition than in the definition by Weiss et al. ${ }^{12}$

NCEP ATP III criteria do not include a measure of IR, which has been shown to provide incremental information in assessing cardiovascular disease risk in the nondiabetic population. ${ }^{55}$ NCEP ATP III criteria have been adapted for US children and adolescents; other populations may have different normal reference ranges for criteria of the definition. ${ }^{56-59}$ In the NCEP ATP III definition, a unique cutoff value for TGs and HDL-C is used that may lead to misclassification of dyslipidemia. Age- and sex-specific fluctuation in lipid values is a characterization of this life period ${ }^{56-58}$ that has been less valued in NCEP ATP III criteria than other criteria. In the present study the largest disagreement between the two definitions used was found for HDL-C.

As there is not a standardized and internationally accepted definition for pediatric MS, it is difficult to compare the pediatric and adolescent MS frequencies reported in different countries. ${ }^{13}$ Not only discrepancies in the definition of individual components of the syndrome but also normal thresholds used in different studies can have an impact on the identification of MS prevalence. ${ }^{15}$

The evaluation of risk factors is more complicated in children, because of the requirement for age- and sexappropriate values that may lead to less frequent identification of the syndrome. ${ }^{17}$ The literature is limited with regard to the usefulness of the identification of MS in adolescents, as the diagnosis of MS is more complicated in this age group.

The most important limitation of the present study is its cross-sectional design. The selection of cases was based on referred children and adolescents, which appears as a limitation but, with respect to an increasing prevalence of obesity, as it highlights the importance of screening of metabolic risk factors in this population it also becomes a strength of the study.
Doubts and discussions exist about which criteria to use. The prevalence of MS varied according to the diagnostic criteria used. The higher prevalence was detected by the NCEP ATP III criteria, the parameters of which include higher cutoff values for HDL and TGs, and therefore the NCEP ATP III criteria are able to diagnose a larger number of children and adolescents at metabolic risk.

\section{Conclusion}

The prevalence of MS in children and adolescents depends on the criteria chosen and their respective cutoff points. To avoid possible under- or overestimation of the prevalence of MS, the use of nationwide specific cutoff values would be helpful and seems likely to give more reliable results. The samples in this study were from clinic-based series of overweight and obese children and adolescents seeking medical care; a survey with comparable methodology on national populations, in order to assess obesity and MS prevalence in youth, should be taken.

\section{Acknowledgments}

The authors would like to thank the staff of the Center for Clinical Research at Qazvin Children Hospital, affiliated to the Qazvin University of Medical Sciences, and Dr Toktam Karimzadeh for their help in preparing this paper. The authors would also like to thank Mrs Shiva Esmaeili for her statistical consultation. This research was officially registered as project No 216 at the College of Medicine, Qazvin University of Medical Sciences.

\section{Disclosure}

The authors report no conflicts of interest in this work.

\section{References}

1. De Onis M, Blössner M. Prevalence and trends of overweight among preschool children in developing countries. Am J Clin Nutr. 2000; 72(4):1032-1039.

2. Ogden CL, Flegal KM, Carroll MD, Johnson CL. Prevalence and trends in overweight among US children and adolescents, 1999-2000. JAMA. 2002;288(14):1728-1732

3. Lobstein T, Baur L, Uauy R; IASO International Obesity Task Force. Obesity in children and young people: a crisis in public health. Obes Rev. 2004;5(Suppl 1):4-104.

4. Perichart-Perera O, Balas-Nakash M, Schiffman-Selechnik E, BarbatoDosal A, Vadillo-Ortega F. Obesity increases metabolic syndrome risk factors in school-aged children from an urban school in Mexico City. J Am Diet Assoc. 2007;107(1):81-91.

5. Freedman DS, Dietz WH, Srinivasan SR, Berenson GS. The relation of overweight to cardiovascular risk factors among children and adolescents: the Bogalusa Heart Study. Pediatrics. 1999;103(6 Pt 1):1175-1182.

6. Hanefeld M, Leonhardt W. The metabolic syndrome [Das metabolische syndrom]. Dtsch Gesundheitsw. 1981;36:545-551. [German.]

7. Reaven GM. Banting lecture 1988: role of insulin resistance in human disease. Diabetes. 1988;37(12):1595-1607. 
8. Levitt NS, Lambert EV. The foetal origins of the metabolic syndrome: a South African perspective. Cardiovasc J S Afr. 2002;13(4):179-180.

9. Ozanne SE, Hales CN. Early programming of glucose-insulin metabolism. Trends Endocrinol Metab. 2002;13(9):368-373.

10. Onat A, Ceyhan K, Başar O, Erer B, Toprak S, Sansoy V. Metabolic syndrome: major impact on coronary risk in a population with low cholesterol levels: a prospective and cross-sectional evaluation. Atherosclerosis. 2002;165(2):285-292.

11. Kelishadi R, Gouya MM, Adeli K, et al. Factors associated with the metabolic syndrome in a national sample of youths: CASPIAN Study. Nutr Metab Cardiovasc Dis. 2008;18(7):461-470. Epub November 1, 2007.

12. Weiss R, Dziura J, Burgert TS, et al. Obesity and the metabolic syndrome in children and adolescents. $N$ Engl J Med. 2004;350(23):2362-2374.

13. López-Capapé M, Alonso M, Colino E, Mustieles C, Corbatón J, Barrio R. Frequency of the metabolic syndrome in obese Spanish pediatric population. Eur J Endocrinol. 2006;155(2):313-319.

14. Lambert M, Paradis G, O’Loughlin J, Delvin EE, Hanley JA, Levy E. Insulin resistance syndrome in a representative sample of children and adolescents from Quebec, Canada. Int J Obes Relat Metab Disord. 2004;28(7):833-841.

15. Goodman E, Daniels SR, Morrison JA, Huang B, Dolan LM. Contrasting prevalence of and demographic disparities in the World Health Organization and National Cholesterol Education Program Adult Treatment Panel III definitions of metabolic syndrome among adolescents. J Pediatr. 2004;145(4):445-451.

16. De Ferranti SD, Gauvreau K, Ludwig DS, Neufeld EJ, Newburger JW, Rifai N. Prevalence of the metabolic syndrome in American adolescents: findings from the Third National Health and Nutrition Examination Survey. Circulation. 2004;110(16):2494-2497. Epub October 11, 2004.

17. Love-Osborne KA, Nadeau KJ, Sheeder J, Fenton LZ, Zeitler P. Presence of the metabolic syndrome in obese adolescents predicts impaired glucose tolerance and nonalcoholic fatty liver disease. J Adolesc Health. 2008;42(6):543-548. Epub March 4, 2008.

18. Eckel RH, Grundy SM, Zimmet PZ. The metabolic syndrome. Lancet. 2005;365(9468):1415-1428.

19. Lustig RH, Weiss R. Disorders of energy balance In: Sperling MA, editor. Pediatric Endocrinology. 3rd ed. Philadelphia: Saunders Elsevier; 2008:788-838.

20. Kong AS, Williams RL, Smith M, et al. Acanthosis nigricans and diabetes risk factors: prevalence in young persons seen in southwestern US primary care practices. Ann Fam Med. 2007;5(3):202-208.

21. World Health Organization. Physical status: the use and interpretation of anthropometry; report of a WHO expert committee. World Health Organ Tech Rep Ser. 1995;854:1-452.

22. National High Blood Pressure Education Program Working Group on High Blood Pressure in Children and Adolescents. The fourth report on the diagnosis, evaluation, and treatment of high blood pressure in children and adolescents. Pediatrics. 2004;114(2 Suppl 4th Report):555-576.

23. Matthews DR, Hosker JP, Rudenski AS, Naylor BA, Treacher DF, Turner RC. Homeostasis model assessment: insulin resistance and betacell function from fasting plasma glucose and insulin concentrations in man. Diabetologia. 1985;28(7):412-419.

24. Esteghamati A, Ashraf H, Khalilzadeh O, et al. Optimal cut-off of homeostasis model assessment of insulin resistance (HOMA-IR) for the diagnosis of metabolic syndrome: third national surveillance of risk factors of non-communicable diseases in Iran (SuRFNCD-2007). Nutr Metab (Lond). 2010;7:26.

25. National Cholesterol Education Program (NCEP) Expert Panel on Detection, Evaluation, and Treatment of High Blood Cholesterol in Adults (Adult Treatment Panel III). Third Report of the National Cholesterol Education Program (NCEP) Expert Panel on Detection, Evaluation, and Treatment of High Blood Cholesterol in Adults (Adult Treatment Panel III) final report. Circulation. 2002;106(25):3143-3421.

26. Altman DG. Practical Statistics for Medical Research. 1st ed. London: Chapman and Hall; 1991.
27. Calcaterra V, Klersy C, Muratori T, et al. Prevalence of metabolic syndrome (MS) in children and adolescents with varying degrees of obesity. Clin Endocrinol (Oxf). 2008;68(6):868-872. Epub November 2, 2007.

28. Pedrosa C, Oliveira BM, Albuquerque I, Simões-Pereira C, Vaz-de-Almeida MD, Correia F. Obesity and metabolic syndrome in 7-9 years-old Portuguese schoolchildren. Diabetol Metab Syndr. 2010;2(1):40

29. Lafortuna CL, Adorni F, Agosti F, et al. Prevalence of the metabolic syndrome among extremely obese adolescents in Italy and Germany. Diabetes Res Clin Pract. 2010;88(1):14-21. Epub January 21, 2010.

30. Viner RM, Segal TY, Lichtarowicz-Krynska E, Hindmarsh P. Prevalence of the insulin resistance syndrome in obesity. Arch Dis Child. 2005;90(1):10-14.

31. Cruz ML, Weigensberg MJ, Huang TT, Ball G, Shaibi GQ, Goran MI. The metabolic syndrome in overweight Hispanic youth and the role of insulin sensitivity. J Clin Endocrinol Metab. 2004;89(1):108-113.

32. Atabek ME, Pirgon O, Kurtoglu S. Prevalence of metabolic syndrome in obese Turkish children and adolescents. Diabetes Res Clin Pract. 2006;72(3):315-321. Epub December 1, 2005.

33. Csábi G, Török K, Jeges S, Molnár D. Presence of metabolic cardiovascular syndrome in obese children. Eur J Pediatr. 2000;159(1-2): 91-94.

34. Druet C, Dabbas M, Baltakse V, et al. Insulin resistance and the metabolic syndrome in obese French children. Clin Endocrinol (Oxf). 2006;64(6):672-678.

35. Ferreira AP, Oliveira CE, França NM. Metabolic syndrome and risk factors for cardiovascular disease in obese children: the relationship with insulin resistance (HOMA-IR). J Pediatr (Rio J). 2007;83(1):21-26. Epub November 28, 2006.

36. Sartorio A, Agosti F, De Col A, Mornati D, Francescato MP, Lazzer S. Prevalence of the metabolic syndrome in Caucasian obese children and adolescents: comparison between three different definition criteria. Diabetes Res Clin Pract. 2007;77(2):341-342. Epub January 22, 2007.

37. Cook S, Weitzman M, Auinger P, Nguyen M, Dietz WH. Prevalence of a metabolic syndrome phenotype in adolescents: findings from the third National Health and Nutrition Examination Survey, 1988-1994. Arch Pediatr Adolesc Med. 2003;157(8):821-827.

38. Ravaglia G, Forti P, Maioli F, et al. Metabolic syndrome: prevalence and prediction of mortality in elderly individuals. Diabetes Care. 2006;29(11):2471-2476.

39. Magi L, Stramenga C, Morosini P; Gruppo di Studio SIMAP. Prevalence of the metabolic syndrome among Italian adults: findings from the SIMAP study. Recenti Prog Med. 2005;96(6):280-283. Italian.

40. Saland JM. Update on the metabolic syndrome in children. Curr Opin Pediatr. 2007;19(2):183-191.

41. Bokor S, Frelut ML, Vania A, et al. Prevalence of metabolic syndrome in European obese children. Int J Pediatr Obes. 2008;3(Suppl 2):3-8.

42. DuBose KD, Stewart EE, Charbonneau SR, Mayo MS, Donnelly JE. Prevalence of the metabolic syndrome in elementary school children. Acta Paediatr. 2006;95(8):1005-1011.

43. Stoddart ML, Blevins KS, Lee ET, Wang W, Blackett PR; Cherokee Diabetes Study. Association of acanthosis nigricans with hyperinsulinemia compared with other selected risk factors for type 2 diabetes in Cherokee Indians: the Cherokee Diabetes Study. Diabetes Care. 2002;25(6):1009-1014.

44. Mukhtar Q, Cleverley G, Voorhees RE, McGrath JW. Prevalence of acanthosis nigricans and its association with hyperinsulinemia in New Mexico adolescents. J Adolesc Health. 2001;28(5):372-376.

45. Weiss R, Taksali SE, Tamborlane WV, Burgert TS, Savoye M, Caprio S. Predictors of changes in glucose tolerance status in obese youth. Diabetes Care. 2005;28(4):902-909.

46. Cruz ML, Goran MI. The metabolic syndrome in children and adolescents. Curr Diab Rep. 2004;4(1):53-62.

47. Reinehr T, de Sousa G, Andler W. Longitudinal analyses among overweight, insulin resistance, and cardiovascular risk factors in children. Obes Res. 2005;13(10):1824-1833. 
48. Voss LD, Metcalf BS, Jeffery AN, Wilkin TJ. IOTF thresholds for overweight and obesity and their relation to metabolic risk in children (EarlyBird 20). Int J Obes (Lond). 2006;30(4):606-609.

49. Nathan BM, Moran A. Metabolic complications of obesity in childhood and adolescence: more than just diabetes. Curr Opin Endocrinol Diabetes Obes. 2008;15(1):21-29.

50. Reinehr T, de Sousa G, Wabitsch M. Changes of cardiovascular risk factors in obese children effects of inpatient and outpatient interventions. J Pediatr Gastroenterol Nutr. 2006;43(4):506-511.

51. Reinehr T, Kleber M, Toschke AM. Lifestyle intervention in obese children is associated with a decrease of the metabolic syndrome prevalence. Atherosclerosis. 2009;207(1):174-180. Epub April 5, 2009.

52. Reinehr T, de Sousa G, Toschke AM, Andler W. Comparison of metabolic syndrome prevalence using eight different definitions: a critical approach. Arch Dis Child. 2007;92(12):1067-1072. Epub February 14, 2007.

53. Invitti C, Maffeis C, Gilardini L, et al. Metabolic syndrome in obese Caucasian children: prevalence using WHO-derived criteria and association with nontraditional cardiovascular risk factors. Int $J$ Obes (Lond). 2006;30(4):627-633.

54. Noto D, Niglio T, Cefalù AB, et al. Obesity and the metabolic syndrome in a student cohort from southern Italy. Nutr Metab Cardiovasc Dis. 2009;19(9):620-625. Epub March 3, 2009.
55. Reilly MP, Wolfe ML, Rhodes T, Girman C, Mehta N, Rader DJ. Measures of insulin resistance add incremental value to the clinical diagnosis of metabolic syndrome in association with coronary atherosclerosis. Circulation. 2004;110(7):803-809. Epub August 2, 2004

56. Porkka KV, Viikari JS, Rönnemaa T, Marniemi J, Akerblom HK. Age and gender specific serum lipid and apolipoprotein fractiles of Finnish children and young adults: the Cardiovascular Risk in Young Finns study. Acta Paediatr. 1994;83(8):838-848.

57. Hickman TB, Briefel RR, Carroll MD, et al. Distributions and trends of serum lipid levels among United States children and adolescents ages 4-19 years: data from the Third National Health and Nutrition Examination Survey. Prev Med. 1998;27(6):879-890.

58. Brotons Cuixart C, Gabriel Sánchez R, Muñiz García J, et al. Pattern of the distribution of total cholesterol and cHDL cholesterol Spanish children and adolescents: RICARDIN Study. Med Clin (Barc). 2000;115(17):644-649. Spanish.

59. Menghetti E, Virdis R, Strambi M, et al. Blood pressure in childhood and adolescence: the Italian normal standards. J Hypertens. 1999; 17(10):1363-1372.
Therapeutics and Clinical Risk Management

\section{Publish your work in this journal}

Therapeutics and Clinical Risk Management is an international, peerreviewed journal of clinical therapeutics and risk management, focusing on concise rapid reporting of clinical studies in all therapeutic areas, outcomes, safety, and programs for the effective, safe, and sustained use of medicines. This journal is indexed on PubMed Central, CAS,

\section{Dovepress}

EMBase, Scopus and the Elsevier Bibliographic databases. The manuscript management system is completely online and includes a very quick and fair peer-review system, which is all easy to use. Visit http://www.dovepress.com/testimonials.php to read real quotes from published authors.

Submit your manuscript here: http://www.dovepress.com/therapeutics-and-clinical-risk-management-journal 